\title{
Novel Methods of Weed Control in Containers
}

Hannah M. Mathers

AdDitIONAL INDEX WORDS. container production, nursery, herbicides, nonchemical alternatives

Summary. Nursery growers estimate that they spend $\$ 500$ to $\$ 4000 /$ acre $(\$ 1235$ to $\$ 9880 /$ ha) of containers for manual removal of weeds, depending upon weed species being removed. Economic losses due to weed infestations have been estimated at about $\$ 7000 /$ acre $(\$ 17,290 /$ ha). Herbicide treated bark nuggets were found extremely effective for weed control in studies during 1998, regardless of whether oxyfluorfen, oryzalin, or isoxaben were applied to the bark. A study conducted in 2000 compared 24 treatments of novel nonchemical alternatives, conventional chemical practices and herbicide treated barks. Four of the best treatments were herbicide treated douglas fir bark, specifically, small $[<1$ inch $(2.5 \mathrm{~cm})$ length] douglas fir nuggets treated with oryzalin at the $1 \times$ rate, large $(>1$ inch length) douglas fir nuggets treated with oryzalin at the $0.5 \times$ rate, small douglas fir nuggets treated with oryzalin at the $0.5 \times$ rate and large douglas fir nuggets treated with flumioxazin at the $1 \times$ rate. The four bark treatments indicated above provided equivalent efficacy and phytotoxicity to Geodiscs. Penn Mulch and Wulpack provided poor weed control. Mori Weed Bag, a black polyethylene sleeve, and Enviro LIDs, a plastic lid provided less control than herbicide treated bark. Compared to the bark alone, herbicide treated bark provides a $\mathbf{1 . 8}$-fold increase in efficacy and a 2.8 -fold extension in duration of efficacy. Compared to the herbicide alone, herbicide treated bark provides a 1.5fold increase in efficacy and a 2.2-fold reduction in phytotoxicity. Of the innovative weed control products tested herbicide treated bark provided the most promising results. The data support that the bark nuggets are possibly acting as slow release carriers for the herbicides or reducing the leaching potential of the herbicides. Recent studies have indicated that the controlled release of herbicides using lignin as the matrix offers a promising alternative technology for weed control.

common definition of a weed is any plant growing where it is
not wanted. Joe Neal, extension weed specialist in nursery
crops at North Carolina State University, says a weed is much more. A weed to a nursery grower is vegetation that 1 ) competes with the crop by absorbing essential nutrients and water, and/or by blocking light or air circulation; 2 ) interferes with harvesting by physically hindering workers; and 3 ) reduces marketability of the crop (Neal, 1999). Weed growth in container-grown nursery stock is a particularly serious problem because available nutrients, air and water are limited to the volume of the container. Nursery growers estimate they spend $\$ 500$ to $\$ 4000 /$ acre for manual removal of weeds, depending upon the weed species being removed (Monrovia Nursery Co., personal communications). Reduction of this expense with improved weed control methodologies would have a significant impact on the industry.

Department of Horticulture and Crop Science, The Ohio State University, 2001 Fyffe Court, Columbus, OH 43210

We acknowledge the Oregon Department of Agriculture Nursery Research and Agricultural Research Foundation, the Horticulture Research Institute, the J. Frank Schmidt Family Charitable Trust and Valent USA Corp. for provision of funding for this research. I would also like to acknowledge the technical assistance of Neil C. Bell, Heidi J. Williams, and Alison L. Henderson, Oregon State University, NWREC, Aurora, and Jim Frelich, The Scotts Co., Gervais, Ore. Salaries and research support provided in part by state and federal funds appropriated to the Ohio Agricultural Research and Development Center, The Ohio State University. Manuscript no. HCS $02-15$ 
Weed problems in container nurseries are not limited to higher plants. Lower plant forms such as silver thread mosses (Bryum argenteum) and common liverwort (Marchantia polymorpha) are also problematic weeds. Problems associated with herbicide use in container production include improper calibration, herbicide runoff from plastic or gravel (especially when chemicals fall between containers) and the need for multiple applications. As with other crops, off-site movement of pesticides through herbicide leaching, runoff and spray drift is a concern facing nursery growers. A typical method of container weed control is to broadcast granular herbicides with a cyclone spreader over the top of stock. Depending on the growth habit and container spacing, nontarget loss (herbicide falling between pots) can be as high as 86\% (Gilliam et al., 1992). Many container nurseries make three to five granular herbicide applications annually, resulting in significant nontarget herbicide loss.

As a result of increasing financial and environmental concerns, reducing herbicide use while still maintaining profitable crop production has been the recent focus of considerable research. Mulching with products such as bark, hazelnut shells, peanut hulls, cocoa shells, rice hulls and corn gluten meal or oyster shells has been advocated for suppression of serious weed problems like liverwort (Suttle, 1996; Svenson, 2002). Mori Nurseries in Niagara-On-The-Lake, Ontario, Canada, have researched weed control using polyethylene sleeves with punched holes. Plastic LIDs called Enviro LIDs (Enviro LID, Langley, British Columbia, Canada) that fit over the top of the container, with punched holes for watering, have also been investigated by nursery growers. Various weed control discs such as Texel Geodisc (Texel USA Inc., Hendersonville, N.C.) a needlepunched, nonwoven polypropylene fabric treated on one side with SpinOut (Griffin LLC, Valdosta, Ga.), coating slow-release fertilizers with preemergent herbicides and horticultural collars, discussed below have been examined (Derr, 1994). In 1998 we at the Oregon State University, North Willamette Research and Extension Center, investigated bark nuggets and controlled-release fertilizer treated with preemergent herbicides for container weed control. A further study was con- ducted in 2000 to compare the herbicide treated bark weed control method with various new techniques of container weed control. This study had two objectives: 1) determine the efficacy and duration of weed control of two mulches, one plastic sleeve, one plastic lid, one weed control disc, two sizes of bark coated with various preemergent herbicides, one new herbicide with a novel chemistry and two conventional chemical controls; and, 2 ) assess potential phytotoxicity of the different methods. This article discusses several novel methods of container weed control and compares the findings of other researchers to the results of our trials, emphasizing the herbicide treated mulches.

\section{Materials and methods}

In the 1998 and 2000 trials, phytotoxicity was evaluated on three species, a deciduous shrub, 'Emerald Gaiety' euonymus (Euonymus fortunei); a conifer, 'Gold cone' common juniper (Juniperuscommunis); and a broadleaf evergreen, 'Rosebud' azalea (Rhododendronspp.) transplanted as bareroot cuttings about 12 inches $(30.5 \mathrm{~cm})$ in length into l-gal (3.8-L) pots and placed in full sun. A 3:1 mix of bark mulch [ 1 inch or less] and peat was used. Plants were potted on 1 June in 1998 and 2000, application of treatments occurred on 2 and 3 June of 1998 and 2000. Plants were watered by over head irrigation daily for the duration of the trial. One-gallon containers, without an ornamental plant, were used for the efficacy experiments. One-quarter teaspoon $(1.167 \mathrm{~mL})$ of seeds per pot of common chickweed (Stellaria media), annual bluegrass (Poa annua) and prostrate spurge (Euphorbia maculata) were broadcast over the container surfaces in the efficacy evaluations, just before application of the prepared herbicide-treated carriers. Douglas fir (Pseudotsuga menziesii) bark nuggets that were $>1$ inch in length were used. Only four to five nuggets were placed on the surface of each pot (Fig. 1). Containers were arranged in a completely randomized design with five replications per treatment in the efficacy evaluations, and per treatment in each plant species in the phytotoxicity evaluations. Vegetative tissue of the weeds present was harvested, dried for $48 \mathrm{~h}$ at $157^{\circ} \mathrm{F}(70$ ${ }^{\circ} \mathrm{C}$ ) and dry weights were determined (Koncal et al., 1981). A visual rating score on a scale of 1 to 10 was also used to evaluate efficacy where $0=$ no control, $10=$ complete control, and $\geq 7=$

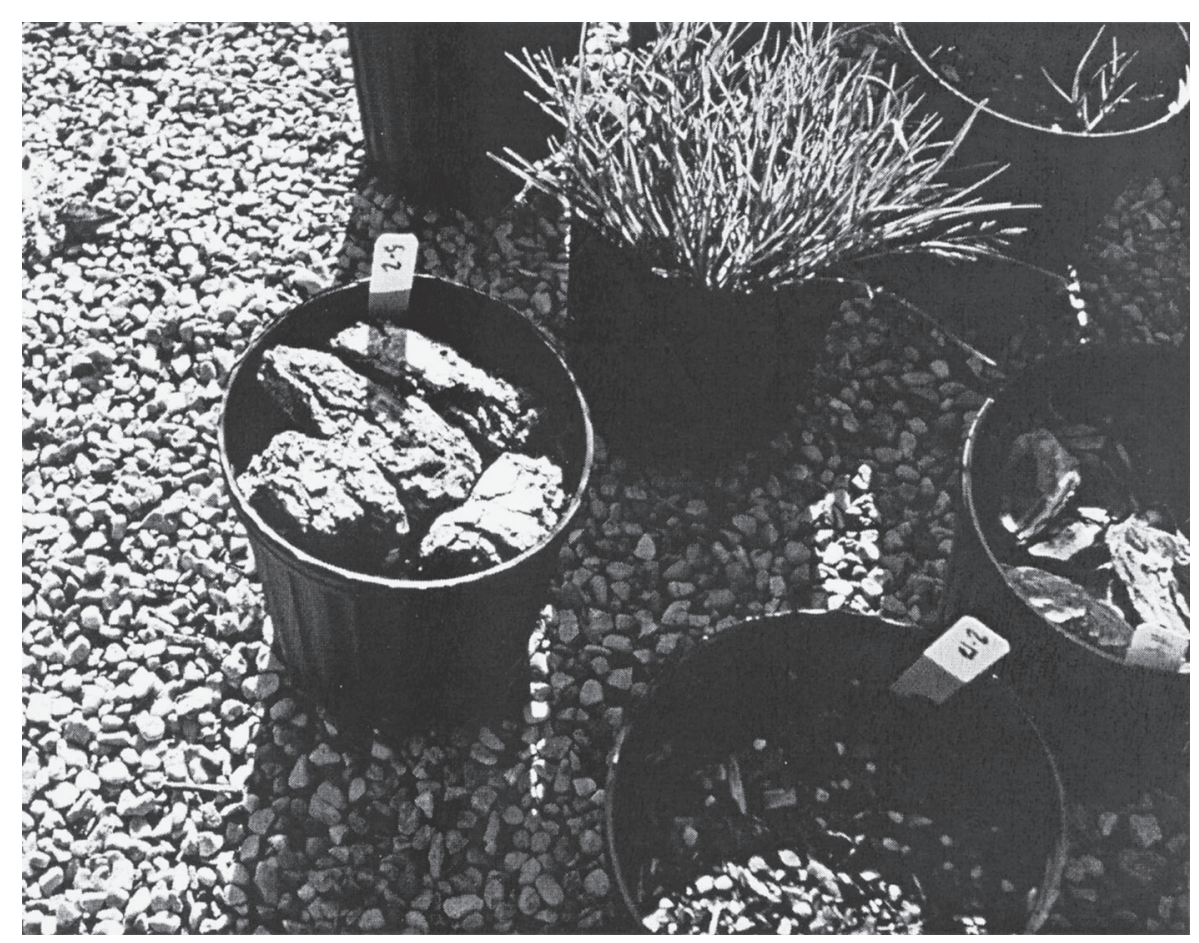

Fig. 1. Placement of herbicide treated douglas fir barknuggets on containers. Herbicide treated bark exhibited considerable efficacy regardless of preemergent herbicide used. Placement prevented germination of weed seeds in exposed areas where they could have germinated. Untreated control pot in background. 


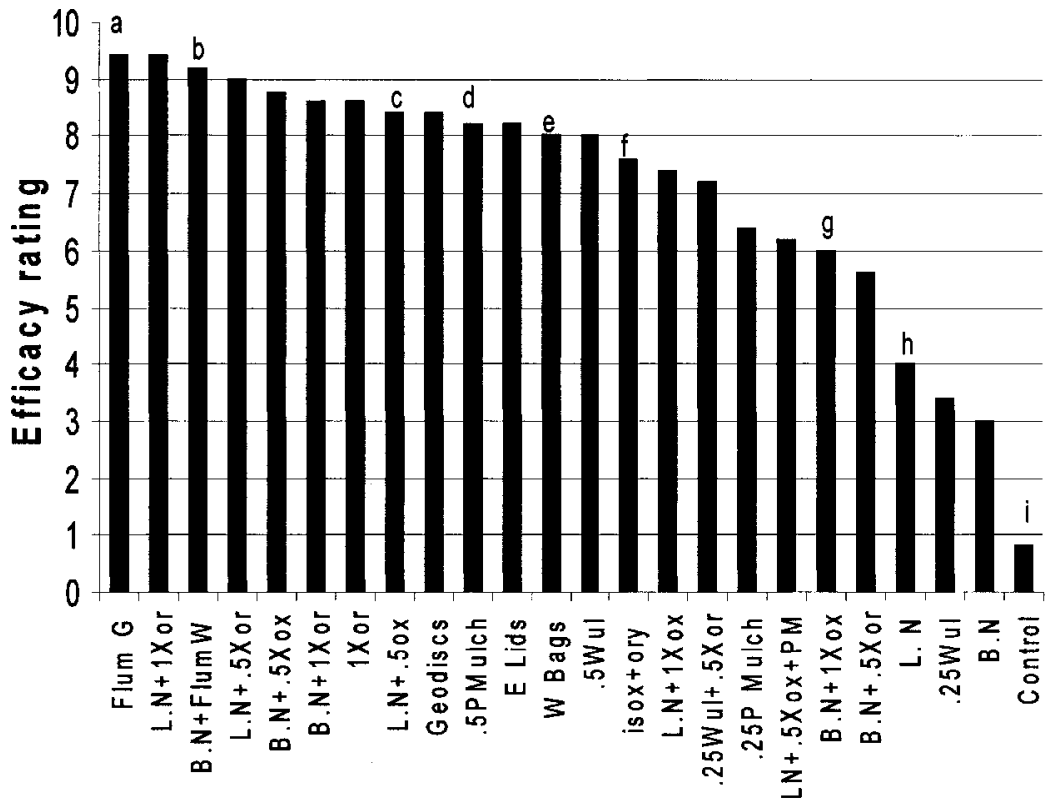

Treatment

commercially acceptable. A visual rating score of 1 , no injury, to 10 , complete kill, and with 3 or below, commercially acceptable, was used to evaluate phytotoxicity. Shoot growth was also harvested and dry weights determined as an evaluation of phytotoxicity.

In 1998, large (>1 inch) douglas fir bark nuggets were sprayed with 1 $\mathrm{lb} /$ acre $\left(1.12 \mathrm{~kg} \cdot \mathrm{ha}^{-1}\right)$ a.i. oxyfluorfen (Goal $2 \times \mathrm{L}$; Dow AgroSciences, Indianapolis, Ind.), $2 \mathrm{lb} /$ acre $\left(2.24 \mathrm{~kg} \cdot \mathrm{ha}^{-1}\right)$ a.i. oryzalin (Surflan AS; Dow AgroSciences), or $1 \mathrm{lb} / \mathrm{acre}$ a.i. isoxaben (Gallery 75DF; Dow AgroSciences). Treated bark was applied at a rate of about four nuggets per pot. The three herbicides indi-

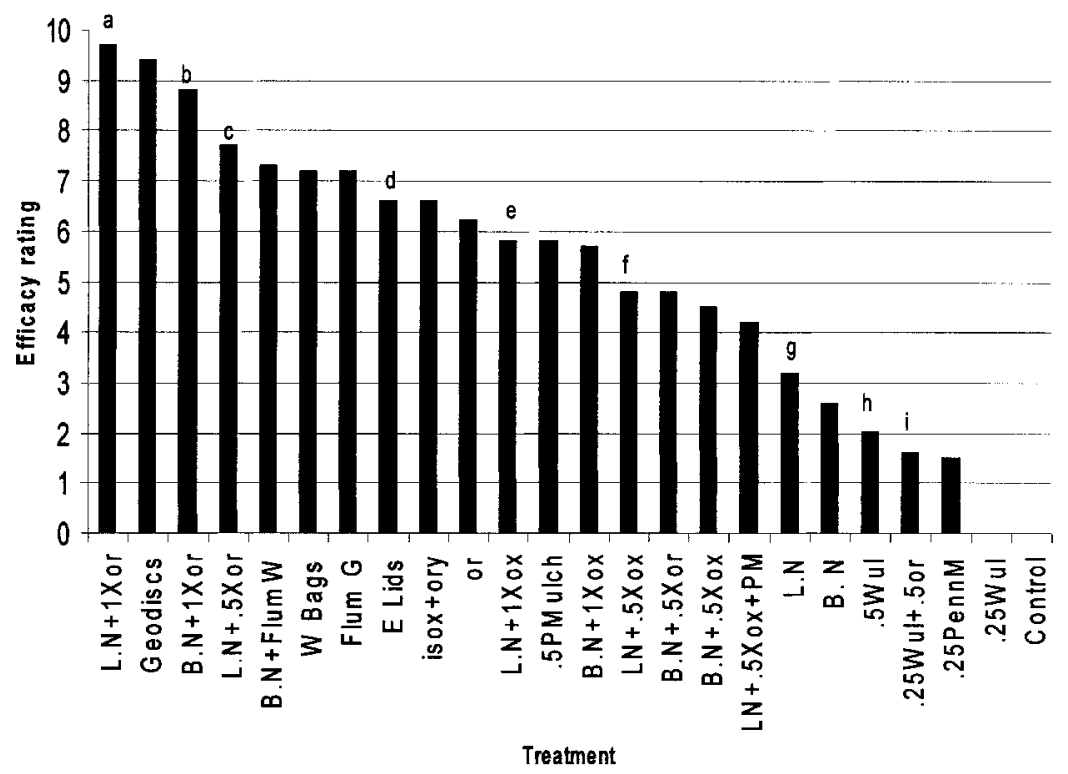

Fig. 2. Efficacies of various weed control treatments in 2000 evaluated as rated scores ( 0 to 10 , where $\geq 7$ is commercially acceptable) at $45 \mathrm{~d}$ after treatment. Different letters signify the least significant difference at $\boldsymbol{P}=\mathbf{0 . 0 5}$. Bars represent the means of five replications. Flum $\mathbf{G}=$ flumioxazin granular, Flum W = flumioxazin wettable dispensible granular, $0 x=$ oxyfluorfen, or = oryzalin, $1 \times=1 \times$ label rate, $.5 \times=$ $0.5 \times$ label rate, $L . N .=1$ little $[<1$ inch $(2.5 \mathrm{~cm})]$ douglas fir nuggets, B.N. = big ( $>1$ inch) douglas fir nuggets, PMulch $=$ PennMulch, .5PMulch $=$ Penn Mulch applied at 0.5 inch (1.27 cm), .25PMulch $=$ PennMulch applied at 0.25 inch $(0.635 \mathrm{~cm}), \mathrm{E}$ Lids $=$ Environ Lids, $\mathrm{W}$ Bags $=$ Mori Weed Bags, Wul = Wulpack, .5 Wul = Wulpack applied at $0.5 \mathrm{inch}, \mathrm{Wul}=$ Wulpack, .25 Wul = Wulpack applied at $0.25 \mathrm{inch}$, isox+ory = isoxaben + oryzalin, L.N .5 $\times$ oxy+PM= little nuggets $+0.5 \times$ rate of oxyfluorfen + PennMulch applied at 0.25 inch.

Apex 21-5-6 (21N-2.2P $5.28 \mathrm{~K}, 5$ month formulation; J.R. Simplot Company, Boise, Idaho), Osmocote 22-3$8(22 \mathrm{~N}-1.32 \mathrm{P}-7.04 \mathrm{~K}, 5$ - to 6 -month formulation; The Scotts Co., Marysville, Ohio), and Osmocote microfertilizer $18-5-9(18 \mathrm{~N}-2.2 \mathrm{P}-7.9 \mathrm{~K}$, 5- to 6-month formulation; The Scotts Co.) spread evenly, one layer thick, on a polyethylene sheet. The fertilizers treated and untreated were applied at $0.35 \mathrm{oz}(10 \mathrm{~g})$ per pot. Two preformulated preemergent treated fertilizers were also tested in 1998, oxadiazon + pendimethalin $+28 \mathrm{~N}-0 \mathrm{P}-0 \mathrm{~K}$ (Kansel Plus; The Scotts Co.) at $0.04 \mathrm{oz}(1.2$ g) per pot and oxadiazon $+21 \mathrm{~N}-0 \mathrm{P}-$ 0K (1.5\% Ronstar; The Scotts Co.) at

$0.04 \mathrm{oz}$ per pot. There were 18 treatments in 1998 study; 12 of the treatments were fertilizer treatments, 4 Apex treatments, 4 Osmocote treatments, and 4 Osmocote microfertilizer treatments. These four fertilizer treatments were the combinations of without herbicide or with oxyfluorfen, oryzalin or isoxaben. Three of the 18 treatments were bark treatments with the three herbicides listed and the three other

Fig. 3. Efficacies of various weed control treatments in 2000 evaluated as rated scores ( 0 to 10 , where $\geq 7$ is commercially acceptable) at $130 \mathrm{~d}$ after treatment. Different letters signify the least significant difference at $\boldsymbol{P}=\mathbf{0 . 0 5}$. Bars represent the means of five replications. Flum W = flumioxazin wettable dispensible granular, Flum $\mathbf{G}=$ flumioxazin granular, $o x=$ oxyfluorfen, or = oryzalin, $1 \times=1 \times$ label rate, $.5 \times=0.5 \times$ label rate, $L . N$. $=$ little $[<1$ inch $(2.5 \mathrm{~cm})$ douglas fir nuggets, B.N. = big (>l inch) douglas fir nuggets, PMulch = PennMulch, .5PMulch = Penn Mulch applied at 0.5 inch $(1.27 \mathrm{~cm})$, .25PMulch $=$ PennMulch applied at 0.25 inch $(0.635 \mathrm{~cm}), \mathrm{E}$ Lids = Environ Lids, W Bags = Mori Weed Bags, Wul = Wulpack, .5 Wul = Wulpack applied at 0.5 inch, Wul= Wulpack, .25 Wul = Wulpack applied at 0.25 inch, isox+ory = isoxaben + oryzalin, L.N .5 $\times$ ox + PM= little nuggets $+0.5 \times$ rate of oxyfluorfen + PennMulch applied at 0.25 inch. 
treatments were the unfertilized control, oxadiazon + pendimethalin + $28 \mathrm{~N}-0 \mathrm{P}-0 \mathrm{~K}$ and oxadiazon $+21 \mathrm{~N}-$ $0 \mathrm{P}-0 \mathrm{~K}$. The 14 fertilizer treatments received no additional fertilizer applications for the duration of the trial. The bark treatments received Apex 21-5-6 (5-month formulation) preplant incorporated and the control received no fertilizer.

In 2000 there were additional treatments for a total of 24 treatments evaluated (Fig. 2). The herbicide treated fertilizers were not evaluated in 2000. Two sizes of douglas fir bark nuggets, large $>1$ inch in length $(>2.54$ $\mathrm{cm})$ and small $<1$ inch in length $(<2.54$ $\mathrm{cm})$, were evaluated in 2000 . The nuggets were laid out on a flat piece of plastic one layer thick to be sprayed with $0.5 \mathrm{lb} /$ acre $\left(0.56 \mathrm{~kg} \cdot \mathrm{ha}^{-1}\right)$ and $\mathrm{l}$ lb/acre a.i. oxyfluorfen or 1 and $2 \mathrm{lb} /$ acre a.i. oryzalin. The large nuggets were also treated with $0.34 \mathrm{lb} /$ acre $\left(0.38 \mathrm{~kg} \cdot \mathrm{ha}^{-1}\right)$ a.i. flumioxazin (SureGuard WDG; Valent USA Corp., Walnut Creek, Calif.). The mulches were allowed to dry for 24 to $48 \mathrm{~h}$ before putting them into the pots at one layer thick. The herbicide treated bark was compared to a control (weedy check), direct sprays of the herbicides and mulch alone. Two granular preemergent herbicides at their $1 \times$ rate, isoxaben $0.5 \%$ (Snapshot 2.5TG; Dow AgroSciences) at $100 \mathrm{lb} /$ acre product and flumioxazin (Broadstar 0.17G, Valent USA Corp.) at $0.25 \mathrm{lb} /$ acre a.i., and several other nonchemical weed control products were also evaluated in 2000. The studies were evaluated for phytotoxicity and efficacy at 70 and $150 \mathrm{~d}$ after treatment (DAT) in 1998 and 45 (Fig. 2) and 130 (Fig. 3) DAT in 2000. The containers were fertilized by slow release fertilizer Apex 21-5-6 and watered by over head irrigation as required. In 1998, the control received no fertilizers or herbicide applications. The treatment effects were compared by analysis of variance [General Linear Model (GLM) procedure; SAS Institute Inc., Cary, N.C.). Fisher's least significance difference test was used to compare means (SAS Institute Inc.). The type IV sum of squares analyses was performed for the unbalanced treatment structure.

\section{Weed control procedures}

The most common type of weed control in ornamental production is chemical control. The present era of herbicide controls was launched by the tremendous success of 2, 4-D introduced in 1946. Generally, only preemergent herbicides are used in container culture. Postemergent herbicides can be used in noncrop areas beneath propagation benches or in the container yard between crops. Postemergent herbicides can also be used, with great care, around the plant in the container when particularly difficult weeds become established. Difficult to control weeds include pearlwort (Sagina procumbens), snapweed (Cardamine spp.) and annual bluegrass. Once the snapweed, annual bluegrass, or pearlwort are dead, preemergents are then applied.

Coating broadcast fertilizers with preemergent herbicides has also been recently examined in agronomic crops such as corn with some success (Koscelny and Peeper 1996; Rabaey and Harvey 1994). Coating of slowrelease fertilizer products with preemergent herbicides could have three advantages in nursery container culture: 1) chemical rates could be lowered (Derr 1994); 2) efficacy could be enhanced and/or extended making proper timing of application easier (Derr 1994); and, 3 ) application would be simplified and safety enhanced.

Of the fertilizers treated with preemergents that we tested in 1998 only the two preformulated products, oxadiazon + pendimethalin $+28 \mathrm{~N}-$ $0 \mathrm{P}-0 \mathrm{~K}$ and oxadiazon $+21 \mathrm{~N}-0 \mathrm{P}-0 \mathrm{~K}$ provided effective weed control (Fig. 4 ). However, these products received nonacceptable ratings for weed control 150 DAT (data not shown). Our results indicate that only the Osmocote microfertilizer may have absorbed any of the applied chemical, as only the Osmocote microfertilizer treated with preemergent herbicides showed any preemergent activity (Fig. 4) in the trial. The Osmocote and Apex treated with oxyfluorfen, oryzalin or isoxaben were ineffective (Fig. 4). Perhaps if we had used alcohol or ethel-glycol as a carrier to deliver the preemergent herbicide sprays to the fertilizers versus water we may have had better uptake of the herbicides into the fertilizer perils.

\section{Other unique products}

Discs AND disc simulators.

Probably the best alternative to chemical weed control (although it contains copper) in containers are GeoDiscs (Appleton and French, 2000). The Spinout product contains copper hydroxide. The copper hydroxide acts to prevent weed seed germination when weed seeds fall onto the container surface with the Geodisc in place. The Geodiscs are applied after planting. A space of 0.75 inch $(1.91 \mathrm{~cm})$ or greater needs to be left between the soil surface and the top of the container so the Geodisc will cling to the sides of the pot and prevent fly away. GeoDiscs have been manufactured to fit different sizes of containers. Two mulching products that simulate the substrate shielding or covering effects of Geodiscs are Wulpack (Wilbro, Inc Norway, S.C.) and PennMulch (Lebanon Seaboard Corporation, Lebanon, Pa.). Wulpack is pelletized sweepings from the shearing floors of sheep operations (Wooten and Neal, 2000) and has $5 \mathrm{~N}-0.44 \mathrm{P}-2.64 \mathrm{~K}$ added. For container weed control Wulpack is used in containers as mulch or in the form of a compressed disc. PennMulch is a pelletized newspaper product, with $1 \%$ nitrogen added. Both Wulpack and PennMulch pellets absorb water and swell to about twice their volume. In a study conducted in North Carolina, in 1999, Wulpack and PennMulch gave good control of most weeds but with some weed species Geodiscs gave better control (Wooten and Neal, 2000). Figure 2 indicates Geodiscs, PennMulch, and Wulpack gave above commercially acceptable weed control at 45 DAT in 2000. However, among these treatments by 130 DAT only the Geodiscs received a commercially acceptable rating (Fig. 3 ).

Researchers have been investigating other types of weed control discs such as one made from crumb rubber in Mississippi. PolyVulc of Vicksburg, Miss., is developing a model or proto type crumb rubber disc for weed control in nursery containers (Tatum et al., 1999). Chong and Purvis (2000) are investigating new-generation weed discs made from cardboard or pressed peat at the University of Guelph, Guelph, Ont., Canada. The corrugated cardboard discs are called Corrudisc and do not hold up well under irrigation (Chong and Purvis, 2000). The pressed peat moss discs are called Biodiscs. They also quickly degrade in normal container culture (Chong and Purvis, 2000).

Appleton and Derr (1990) inves- 


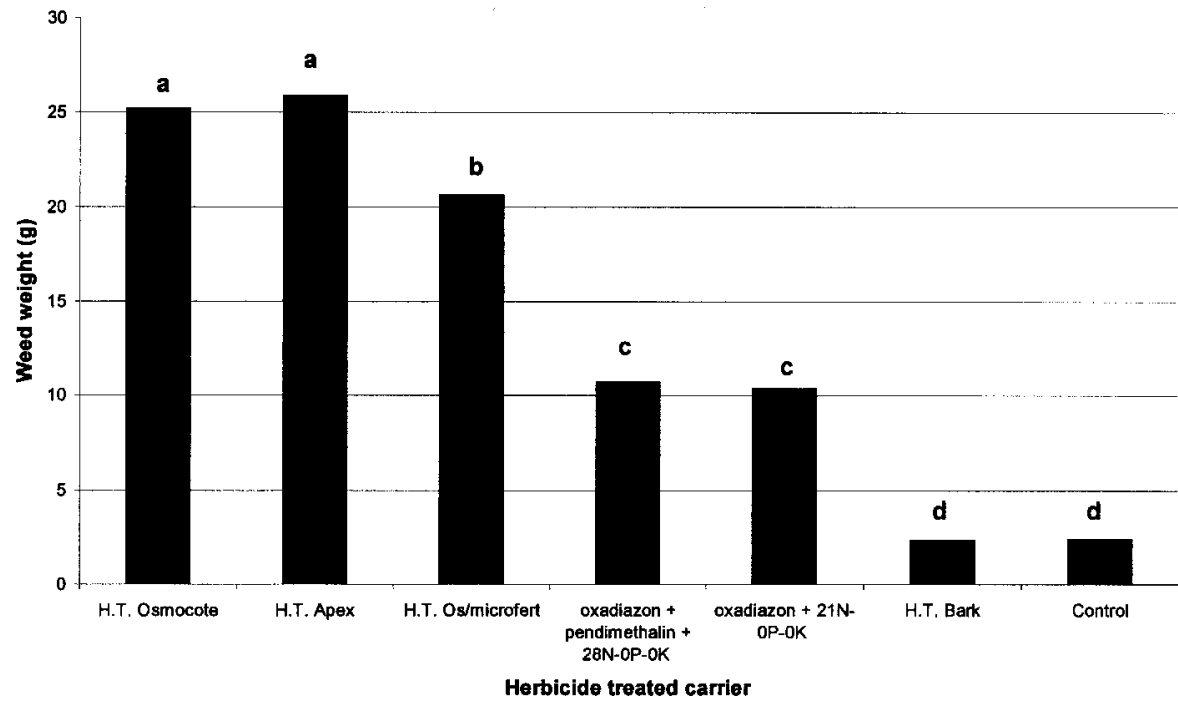

Fig. 4. Efficacy of various preemergent carriers in 1998 expressed as grams of weed weight $(28.35 \mathrm{~g}=1.0 \mathrm{oz})$. Different letters signify the least significant difference at $P=$ 0.05. Bars represent the means of five replications averaged over three herbicides and two evaluation dates, 70 and $150 \mathrm{~d}$ after treatment. The control received no fertilizer or preemergent. The control bar represents five replicates averaged over two evaluation dates. H.T. = herbicide treated, os/microfert = Osmocote microfertilizer.

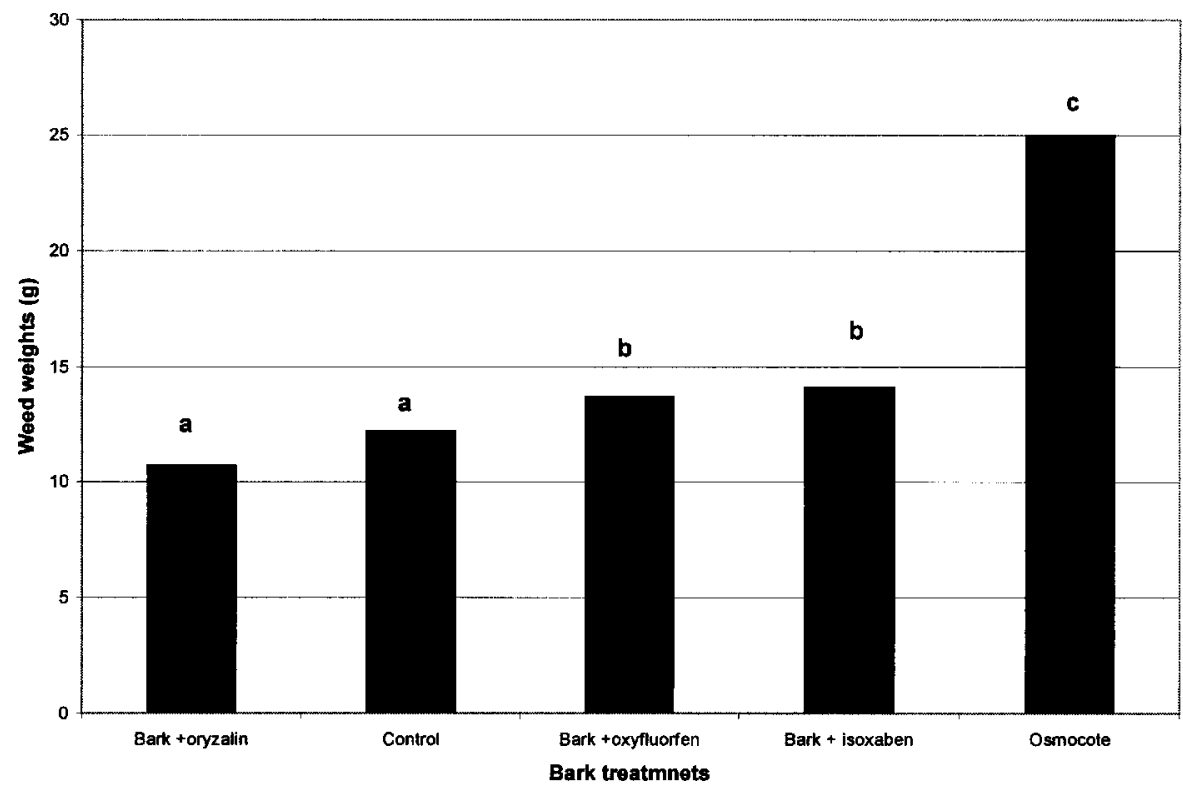

Fig. 5. Efficacy of herbicide-treated bark treatments compared to untreated Osmocote fertilizer in 1998 expressed as grams of weed weight $(28.35 \mathrm{~g}=1.0 \mathrm{oz})$. Bars represent the means of five replications averaged over two evaluation dates, 70 and $150 \mathrm{~d}$ after treatment. The control received no fertilizer or preemergent. Different letters signify the least significant difference at $\boldsymbol{P}=0.05$.

tigated discs composed of two layers of landscape fabric with herbicides and slow-release fertilizers placed between the layers. A slit was cut to allow insertion around plant stems, and the edges of the two fabric layers were sealed, resulting in a horticultural collar that could be placed around containergrown nursery stock after planting. The horticultural collar controlled weeds longer and better than standard herbicide applications to containergrown plants (Derr, 1994).

LIDS AND BAGS. In 2000, the Mori Weed Bags and the Enviro LIDs mentioned above gave above commercially acceptable weed control at 45 DAT (Fig. 2); however, by 130 DAT only the Mori Weed Bags were still providing above commercially acceptable weed control. The weed control of the Mori Weed Bags, however, was significantly less than that provided by four herbicide treated bark treatments (Fig. 3). Mori Nurseries, however, has used these weed bags with success for several years (Chong, 2003). There are no reports in the literature regarding the effectiveness of Enviro LIDs.

NoNHERBICIDE-TREATED MULCHES. Organic mulches control weeds in two ways, inhibition of germination and suppression of weed growth (Borland, 1990; Duryea et al., 1999; Skroch et al., 1992). The effects of mulches on weed control are greatest when the mulch is fresh (Duryea et al., 1999). Pelletized (PennMulch) and crumbled recycled paper products have also been researched as mulches for weed control efficacy. Waste paper is ground with a hammer mill equipped with a series of three screens [the smallest about 0.25 inch $(0.635 \mathrm{~cm})$ ], then compressed using pelletizing equipment to form pellets about $3 / 16 \times 1$ inch $(0.476 \times 2.54 \mathrm{~cm})$ in size (Smith et al., 1998). To develop the crumble product, pellets are put through a granulator with variable pressure plates. These recycled paper products are noncomposted and have a carbon to nitrogen ratio of 500:1 (Smith et al., 1998). Smith et al. (1998), found the recycled paper effective for weed control; however, they indicated that it may not be cost effective for every situation. They concluded that recycled paper products would have merit in the four specific container growing situations: 1) plants grown in containers larger than 10 gal $(37.9 \mathrm{~L})$, where increased pot spacing results in greater nontarget herbicide loss; 2) environmentally sensitive areas near surface water bodies; 3 ) plants that are difficult to weed due to thorns or spines; and 4) in enclosed structures where herbicide use is restricted (Smith et al., 1998). In 2000, we found PennMulch did not provide effective weed control applied at 0.25 or 0.5 inch $(1.27 \mathrm{~cm})$ at 130 DAT (Fig. 3).

The most commonly used mulches in ornamentals are barks. Skroch et al. (1992), in a study of three bark mulches and two pine needle mulches, found that even when applied at a depth of 3.5 inches $(8.89 \mathrm{~cm})$ the mulches only reduced weed counts by $50 \%$ over the untreated controls. This level of control was well below commercially acceptable. Similarly, in our efficacy study, douglas fir bark 


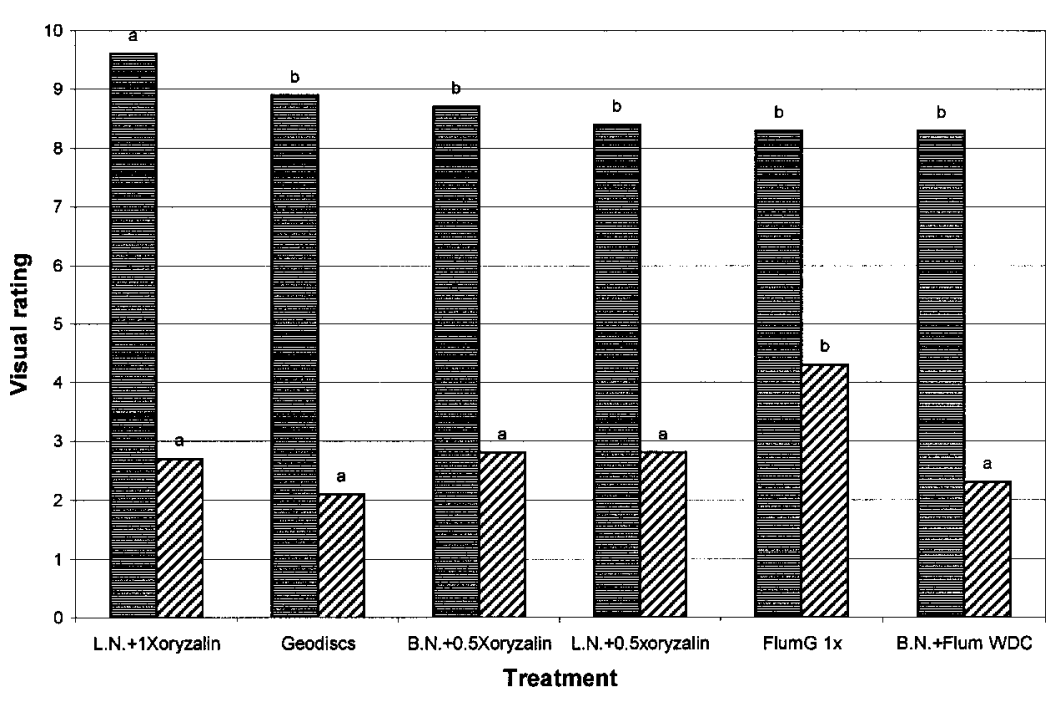

Fig.6. Efficacy and phytotoxicity for the six most efficacious treatments in 2000, evaluated by rated scores (efficacy rated 0 to 10 , where $\geq 7$ commercially acceptable and 10 is complete control; phytotoxicity $\leq 3$ is commercially acceptable) over two evaluation dates. Different letters signify the least significant difference at $P=0.05$. Bars represent the means of five replications averaged over two evaluation dates, 45 and $130 \mathrm{~d}$ after treatment. Flum $\mathrm{W}=$ flumioxazin wettable dispensible granular, Flum G = flumioxazin granular, L.N. = little $[<1$ inch $(2.54 \mathrm{~cm})]$ douglas fir nuggets, B.N. = big (>1 inch) douglas fir nuggets.

mulch applied alone, without herbicide pretreatment, provided less than acceptable weed control at 45 DAT and 130 DAT (Figs. 2 and 3 ).

Herbicide-treated mulches. Mulches that have been pretreated with preemergent herbicides may offer extra advantages for weed control over untreated mulches. The only calibration required would be monitoring the mulch depth to ensure the optimum rate of application (Mathers and Ozkan, 2001). Herbicide treated mulches could be added as a top layer during the filling of pots in assemblyline plantings. The application of preemergent herbicide treated bark nuggets resulted in increased and extended herbicide efficacy in 1998 (Fig. 4) and in 2000 (Fig. 3) compared to the herbicides or mulches applied alone. In 1998, the control, which contained no fertilizer or herbicide, provided equivalent efficacy to the herbicide treated barks (Fig. 3). Without fertilizer no weed seeds germinated in this check. However, without fertilizer the control was also the most phytotoxic treatment (data not shown). The ornamental plants in the control of the phytotoxicity experiment with out fertilizer were severely stunted and chlorotic. Regardless of which of the three preemergents were applied, the herbicide treated barks provided excellent weed control (Fig. 4). However, bark treated with oryzalin had significantly greater efficacy than bark treated with oxyfluorfen or isoxaben (Fig. 5). The herbicide treated douglas fir represented four of the six most efficacious treatments in 2000 at 130 DAT (Figs. 2 and 3 ), their corresponding phytotoxicities were below 2.8 (Fig. 6). Treatment of oryzalin onto douglas fir bark in 2000 provided significantly greater efficacy versus treatments with oxyfluorfen. Little nuggets treated with oryzalin at $2 \mathrm{lb} /$ acre a.i. were the best treatment in 2000 .

Preliminary studies by J. Neal and A. Senesac (unpublished), J. Derr (unpublished), and G. Hogue (unpublished) have shown excellent control of certain weeds with a layer of pine bark mulch containing preemergent herbicides. J. Derr (unpublished) observed increased efficacy with pine bark mulch treated with preemergent herbicide versus mulch alone. Waste paper mulch pretreated with Casoron and covered by an additional layer of waste paper mulch which sealed in the Casoron, gave excellent control of several weed species with no observed phytotoxicity (G. Hogue, unpublished).

\section{Conclusions}

Weed control has become a lead- ing issue in nursery culture for three reasons. First, the increase in irrigation water restrictions and necessity of recirculation ponds in container nursery culture means fewer and fewer herbicides are being registered due to chemical company fears of reapplication onto stock. Second, when the new Food Quality Protection Act (FQPA) of 1996 became law two existing acts were amended, the Federal Insecticide, Fungicide, and Rodenticide Act (FIFRA) and the Federal Food Drug, and Cosmetic Act (FFDCA) [U.S. Environmental Protection Agency (USEPA), 2002]. These amendments changed the way the USEPA regulates pesticides (USEPA, 2002). As a result of these changes the ornamental industry may be facing the loss of pesticide registrations. The loss of herbicide registrations will have a greater impact on the industry than fungicide or insecticide losses. Third, the cost of traditional weed control, chemical applications plus hand weeding, is already the largest pest management cost that growers encounter. In fact, weed control costs far surpass any other form of pest control. New weed control methods that are effective, economical and have reduced environmental impact are needed.

In our experiments in 1998 and 2000 , the herbicide treated mulches were superior in reducing phytotoxicity, increasing efficacy and extending efficacy. We have found that the herbicide treated bark provides a 1.5-fold increase in efficacy over the herbicide applied alone, a 1.8-fold increase compared to the bark alone, a 2.8 -fold extension in duration of efficacy and a 2.2 -fold reduction in phytotoxicity compared to the herbicide alone treatments. Even though greater efficacy is achieved with the herbicide treated bark, phytotoxicity is reduced, probably because the herbicide is never directly applied on or near the plant material. Present data indicates that the bark nuggets bind the herbicides and possibly act as slow release carriers for the herbicides or reduce the leaching potential of the herbicides. Recent studies have indicated that the application of preemergent herbicides onto organic mulches reduced herbicide leaching by $35 \%$ to $74 \%$ compared with bare soil preemergent herbicide applications (Knight et al., 2001). Recent studies have also indicated that the controlled release of herbicides 
using lignin as the matrix offers a promising alternative technology for weed control (Oliveira et al., 2000).

\section{Literature cited}

Appleton, B. and J. Derr. 1990. A multiple chemical delivery system for containergrown nursery stock. Proc. S. Nursery Assn. Res. Conf. 35:68-70.

Appleton, B. and S. French. 2000. Weed suppression for container-grown willow oak using copper-treated fabric discs. HortTechnology 10: 204-206.

Borland, J. 1990. Mulch. Amer. Nurseryman 172:132-143.

Chong, C. 2003. Experiences with weed discs and other nonchemical alternatives for container weed control. HortTechnology 13(1):23-27.

Chong, C. and P. Purvis. 2000. Searching for nonchemical alternatives to container weed control. Landscape Trades 22:48.

Derr, J.F. 1994. Innovative herbicide application methods and their potential for use in the nursery and landscape industries. HortTechnology 4:345-350.

Duryea, M.L., J. English, and L.A. Hermansen. 1999. A comparison of landscape mulches: Chemical, allelopathic, and decomposition properties. J. Arboricult. 25:88-96.
Gilliam, C.H., D.C. Fare, and A. Beasley. 1992. Nontarget herbicide losses from granular Ronstar to container nurseries. J. Environ. Hort. 10:175-176.

Knight, P.R, C.H. Gilliam, S.L. File, and D. Reynolds. 2001. Mulches reduce herbicide loss in the landscape. Proc. S. Nursery Assn. Res. Conf. 46:461-463.

Koncal, J.J., S.F. Gorske, and T.A. Fretz. 1981. Slow-release herbicide formulation for weed control in container-grown plants. HortScience 16:83-84.

Koscelny, J.A. and T.F. Peeper. 1996. Herbicides impregnated onto granular fertilizer carriers for broadleaf weed control in winter wheat. Weed Technol. 10:526-530.

Mathers, H. and E. Ozkan. 2001. Herbicide treated mulches. Nursery Mgt. Prod. 17(1):61-66.

Neal, J. 1999. Weeds and you. Nursery Mgt. Prod. 15:60-62, 64-65.

Oliveira, S.C., F.M. Pereira, A. Ferraz, F.T. Silva, and A.R. Goncalves. 2000. Mathematical modeling of controlled-release systems of herbicides using lignins as matrices. Appl. Biochem. Biotechnol. 8486:595-615.

Rabaey, T.L. and R.G. Harvey. 1994. Efficacy of corn herbicides applied at reduced rates impregnated in dry fertilizer. Weed Technol. 8:830-835.
Skroch, WA., M.A. Powell, T.E. Bilderback, and P.H. Henry. 1992. Mulches: Durability, aesthetics value, weed control, and temperature. J. Environ. Hort. 10:43-45.

Smith, D.R., C.H. Gilliam, J.H. Edwards, J.W. Olive, D.K. Eakes, and J. Williams. 1998. Recycled waste paper as a nonchemical alternative for weed control in container production. J. Environ. Hort. 16:6975 .

Suttle, W. 1996. Weed control in container nurseries. Proc. Weed Control in Nursery and Landscape Short Course, Malaspina Univ. College, Nanaimo, B.C.

Svenson, S. 2002. Control of liverwort in containers. Va. Nursery Landscape Assn. Nwslt. 72(1):72-74.

Tatum, D., K. Johnson, and N. Winter. 1999. The use of crumb rubber for weed control in ornamental containers. Proc. S. Nursery Assn. Res. Conf. 44:407.

U.S. Environmental Protection Agency. 2002. Food Quality Protection Act (FQPA) of 1996. USEPA, Office of Pesticide Programs. 20 Sept. 2002. <http:// www.epa.gov/opppspsl/fqpa>.

Wooten, R.E. and J. Neal. 2000. Evaluations of PennMulch, Wulpack and Geodisc for weed control in containers. Proc. N.E. Weed Sci. Soc. 54:96. 